\title{
The Effect of Heat Transfer on MHD Marangoni Boundary Layer Flow Past a Flat Plate in Nanofluid
}

\author{
D. R. V. S. R. K. Sastry, ${ }^{1}$ A. S. N. Murti, ${ }^{2}$ and T. Poorna Kantha ${ }^{2}$ \\ ${ }^{1}$ Department of Mathematics, Aditya Engineering College, Surampalem, Ardhra Pradesh 533437, India \\ ${ }^{2}$ Deptartment of Engineering Mathematics, GITAM University, Visakhapatnam, Ardhra Pradesh 530023, India
}

Correspondence should be addressed to D. R. V. S. R. K. Sastry; sastry_dev@yahoo.co.in

Received 30 March 2013; Revised 8 May 2013; Accepted 8 May 2013

Academic Editor: Yurong Liu

Copyright ( 2013 D. R. V. S. R. K. Sastry et al. This is an open access article distributed under the Creative Commons Attribution License, which permits unrestricted use, distribution, and reproduction in any medium, provided the original work is properly cited.

\begin{abstract}
The problem of heat transfer on the Marangoni convection boundary layer flow in an electrically conducting nanofluid is studied. Similarity transformations are used to transform the set of governing partial differential equations of the flow into a set of nonlinear ordinary differential equations. Numerical solutions of the similarity equations are then solved through the MATLAB "bvp4c" function. Different nanoparticles like $\mathrm{Cu}, \mathrm{Al}_{2} \mathrm{O}_{3}$, and $\mathrm{TiO}_{2}$ are taken into consideration with water as base fluid. The velocity and temperature profiles are shown in graphs. Also the effects of the Prandtl number and solid volume fraction on heat transfer are discussed.
\end{abstract}

\section{Introduction}

The convection induced by the variations of the surface tension gradients is known as the Marangoni convection. This convection has received great consideration in view of its application in the fields of welding and crystal growth. Also this convection is necessary to stabilize the soap films and drying silicon wafers. During the study of the existence of the steady dissipative layers which occur along the liquidliquid or liquid-gas interfaces, Napolitano [1] first called the boundary layer as the Marangoni boundary layer. Many researchers such as Okano et al. [2], Christopher and Wang [3], Pop et al. [4] and Magyari and Chamkha [5] have investigated the Marangoni convection in various geometries. Al-Mudhaf and Chamkha [6] obtained the similarity solution for the MHD thermosolutal Marangoni convection over a flat surface in the presence of heat generation or absorption with fluid suction and injection. Chen [7] investigated the flow and the heat transfer characteristics on the forced convection in a power law liquid film under an applied Marangoni convection over a stretching sheet. In recent years, the study on convective transport of nanofluids has become one of the popular topics of interest. Nanotechnology takes important part for the development of high performance, compact, and cost-effective liquid cooling systems. Moreover, nanofluids have effective applications in many industries such as electronics, transportation, biomedical, and many more. Nanotechnology has been an ongoing topic of discussion in public health as some of the researchers claimed that nanoparticles could present possible dangers in health and environment. Jang and Choi [8] have introduced nanosized particle in a base fluid, which is also termed nanofluid, for the first time. Arifin et al. [9] have examined the influence of nanoparticles on the Marangoni boundary layer flow using a model proposed by Tiwari and Das [10]. An extended work was done by Buongiorno [11], Daungthongsuk and Wongwises [12], Trisaksri and Wongwises [13], Wang and Mujumdar [14], and Kakaç and Pramuanjaroenkij [15]. Recently Hamid et al. [16] studied the radiation effects on the Marangoni boundary layer flow past a flat plate in nanofluid. In the present paper, we study a numerical solution of MHD heat transfer problem in nanofluid with nanoparticles $\mathrm{Cu}, \mathrm{Al}_{2} \mathrm{O}_{3}$, and $\mathrm{TiO}_{2}$. We also observed the effects of the Prandtl number and solid volume fraction on the Nusselt number. The results are shown graphically. 


\section{Mathematical Formulation}

Consider a steady two-dimensional Marangoni boundary layer flow past a permeable flat plate in a water-based nanofluid containing different types of nano particles like $\mathrm{Cu}$ (Copper), $\mathrm{Al}_{2} \mathrm{O}_{3}$ (Aluminium Oxide), and $\mathrm{TiO}_{2}$ (Titanium dioxide). Assume that the fluid is incompressible and the flow is laminar. Also it is assumed that the base fluid and the particles are in thermal equilibrium and no slip occurs between them. The thermophysical properties of nanoparticles are given in the Table 1. Further, we consider a Cartesian coordinate system $(x, y)$, where $x$ and $y$ are the coordinates measured along the plate and normal to it, respectively, and the flow takes place at $y \geq 0$. Assume that the temperature of the plate is $T_{w}(x)$ and that of the ambient fluid is $T_{\infty}$.

We further assume that the surface tension $\sigma$ is to vary linearly with temperature as

$$
\sigma=\sigma_{0}\left[1-\gamma\left(T-T_{\infty}\right)\right]
$$

where $\sigma_{0}$ is the surface tension at the interface and $\gamma$ is the rate of change of surface tension with temperature (a positive fluid property). It is also assumed that a uniform magnetic field, $H_{0}$ is imposed in the direction normal to the surface (Figure 1). Then, the steady state boundary layer equations for a nanofluid in the Cartesian coordinates are given by

$$
\begin{gathered}
\frac{\partial u}{\partial x}+\frac{\partial v}{\partial y}=0 \\
u \frac{\partial u}{\partial x}+v \frac{\partial u}{\partial y}=\frac{\mu_{\mathrm{nf}}}{\rho_{\mathrm{nf}}} \frac{\partial^{2} u}{\partial y^{2}}-\frac{\sigma}{\rho_{\mathrm{nf}}} H_{0}^{2} u \\
u \frac{\partial T}{\partial x}+v \frac{\partial T}{\partial y}=\alpha_{\mathrm{nf}} \frac{\partial^{2} T}{\partial y^{2}}
\end{gathered}
$$

together with the boundary conditions

$$
\begin{gathered}
v=0, \quad T=T_{\infty}+a x^{2}, \\
\mu_{\mathrm{nf}} \frac{\partial u}{\partial y}=\frac{\partial \sigma}{\partial T} \frac{\partial T}{\partial x} \quad \text { at } y=0, \\
u=0, \quad T=T_{\infty} \quad \text { as } y \longrightarrow \infty .
\end{gathered}
$$

Here $u$ and $v$ are the components of velocity along the $x$ - and $y$-axes, respectively. $T$ is the temperature, $\alpha_{\mathrm{nf}}$ is the thermal diffusivity, $\rho_{\mathrm{nf}}$ is the effective density, $k_{\mathrm{nf}}$ is the effective thermal conductivity, and $\mu_{\mathrm{nf}}$ is the effective viscosity of the nanofluid. Moreover, $a$ is the coefficient of temperature gradient. Consider the following:

$$
\begin{gathered}
\alpha_{\mathrm{nf}}=\frac{k_{\mathrm{nf}}}{\left(\rho C_{p}\right)_{\mathrm{nf}}}, \\
\rho_{\mathrm{nf}}=(1-\phi) \rho_{f}+\phi \rho_{s}, \\
\mu_{\mathrm{nf}}=\frac{\mu_{f}}{(1-\phi)^{2.5}},
\end{gathered}
$$

TABLE 1: Thermophysical properties of pure water and nanoparticles (Oztop and Abu-Nada [17]).

\begin{tabular}{lcccc}
\hline Physical property & Pure water & $\mathrm{Cu}$ & $\mathrm{Al}_{2} \mathrm{O}_{3}$ & $\mathrm{TiO}_{2}$ \\
\hline$\rho\left(\mathrm{kg} / \mathrm{m}^{3}\right)$ & 997.1 & 8933 & 3970 & 4250 \\
$C_{p}(\mathrm{~J} / \mathrm{kg} \mathrm{K})$ & 4179 & 385 & 765 & 686.2 \\
$k(\mathrm{~W} / \mathrm{m} \mathrm{K})$ & 0.613 & 401 & 40 & 8.9538 \\
\hline
\end{tabular}

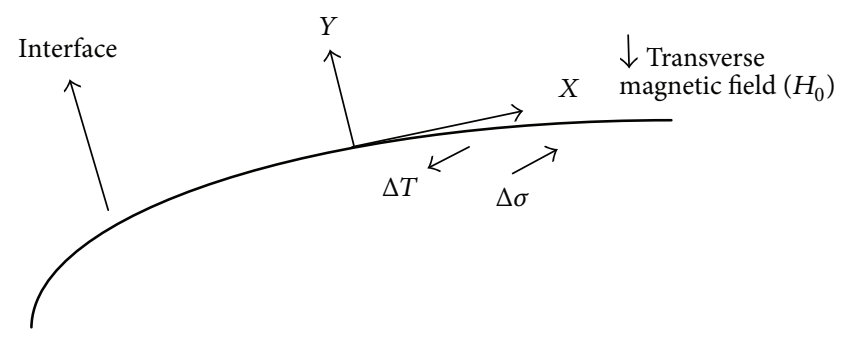

FIgURE 1: Schematic diagram of the problem.

$$
\begin{gathered}
\left(\rho C_{p}\right)_{\mathrm{nf}}=(1-\phi)\left(\rho C_{p}\right)_{f}+\phi\left(\rho C_{p}\right)_{s}, \\
\frac{k_{\mathrm{nf}}}{k_{f}}=\frac{\left(k_{s}+2 k_{f}\right)-2 \phi\left(k_{f}-k_{s}\right)}{\left(k_{s}+2 k_{f}\right)+\phi\left(k_{f}-k_{s}\right)}, \\
a=\frac{\Delta T}{L^{2}},
\end{gathered}
$$

where $\phi$ is the solid volume fraction of the nanofluid, $\rho_{f}$ is the reference density of the fluid fraction, $\rho_{s}$ is the reference density of the solid fraction, $\mu_{f}$ is the viscosity of the fluid fraction, $k_{f}$ is the thermal conductivity of the fluid, $k_{s}$ is the thermal conductivity of the solid, and $\left(\rho C_{p}\right)_{n f}$ is the heat capacity of the nanofluid. $L$ is the length of the surface, and $\Delta T$ is the constant characteristic temperature.

A similarity solution of (2)-(5) is obtained by introducing an independent variable $\eta$ and a dependent variable $f$ in terms of the stream function $\psi$ as

$$
\psi=C_{1} x f(\eta), \quad \eta=C_{2} y,
$$

with $u=\partial \psi / \partial y$ and $v=-\partial \psi / \partial x$.

The constants $C_{1}$ and $C_{2}$ are given by

$$
C_{1}=\left(\frac{\sigma_{0} \gamma a \mu_{f}}{\rho_{f}^{2}}\right)^{1 / 3}, \quad C_{2}=\left(\frac{\sigma_{0} \gamma a \rho_{f}}{\mu_{f}^{2}}\right)^{1 / 3} .
$$

Further, the dimensionless temperature $\theta$ is given by

$$
\theta(\eta)=\frac{T-T_{\infty}}{a x^{2}} .
$$


Substituting (6), (7), (8), and (9) into (3) and (4), we obtain a set of nonlinear ordinary differential equations:

$$
\begin{gathered}
f^{\prime \prime \prime}=(1-\phi)^{2.5}\left[(1-\phi)+\phi \frac{\rho_{s}}{\rho_{f}}\right]\left(f^{\prime 2}-f f^{\prime \prime}\right) \\
+M\left(P_{r}\right)^{1 / 3}\left(k_{f}\right)^{1 / 3}\left(C p_{f}\right)^{-1 / 3}\left(\rho_{f}\right)^{-2 / 3} f^{\prime}, \\
\theta^{\prime \prime}=\frac{\left[(1-\phi)+\phi\left(\rho_{s} C p_{s} / \rho_{f} C p_{f}\right)\right]}{k_{\mathrm{nf}} / k_{f}}\left(2 f^{\prime} \theta-f \theta^{\prime}\right) P_{r},
\end{gathered}
$$

and the boundary conditions become

$$
\begin{gathered}
f(0)=0, \quad \theta(0)=1, \quad \frac{1}{(1-\phi)^{2.5}} f^{\prime \prime}(0)=-2, \\
f^{\prime}(\infty)=0, \quad \theta(\infty)=0,
\end{gathered}
$$

where the magnetic field parameter $M=\sigma^{1 / 3} H_{0}^{2} /(\gamma a)^{2 / 3}$.

Also one can define the surface velocity and the local Nusselt number, respectively, as

$$
\begin{gathered}
u_{w}(x)=\sqrt[3]{\frac{\left(\sigma_{0} \gamma a\right)^{2}}{\rho_{f} \mu_{f}} x f^{\prime}(0),} \\
\mathrm{Nu}_{x}=\frac{x q_{w}(x)}{k_{f}[T(x, 0)-T(x, \infty)]},
\end{gathered}
$$

where $q_{w}(x)$ is the heat flux from the surface of the plate and is given by

$$
q_{w}(x)=-k_{\mathrm{nf}}\left(\frac{\partial T}{\partial y}\right)_{y=0}
$$

Using the above nondimension quantities, one can obtain the local Nusselt number as

$$
\mathrm{Nu}_{x}=-\frac{k_{\mathrm{nf}}}{k_{f}} C_{2} \theta^{\prime}(0) .
$$

Based on the average temperature difference between the temperature of the surface and the ambient fluid temperature we define

$$
\mathrm{Nu}_{L}=-\frac{k_{\mathrm{nf}}}{k_{f}}\left(\frac{\mathrm{Ma}_{L}}{\operatorname{Pr}}\right)^{1 / 3} \theta^{\prime}(0),
$$

where $\mathrm{Ma}_{L}$ is the Marangoni based on $L$ and is defined as

$$
\mathrm{Ma}_{L}=\frac{(\partial \sigma / \partial T)(\Delta T) L}{\alpha_{f} \mu_{f}} .
$$

\section{Results and Discussion}

Numerical solutions were obtained for the effect of the Prandtl number and solid volume fraction on the Marangoni heat transfer in a nanofluid. In this paper, we considered

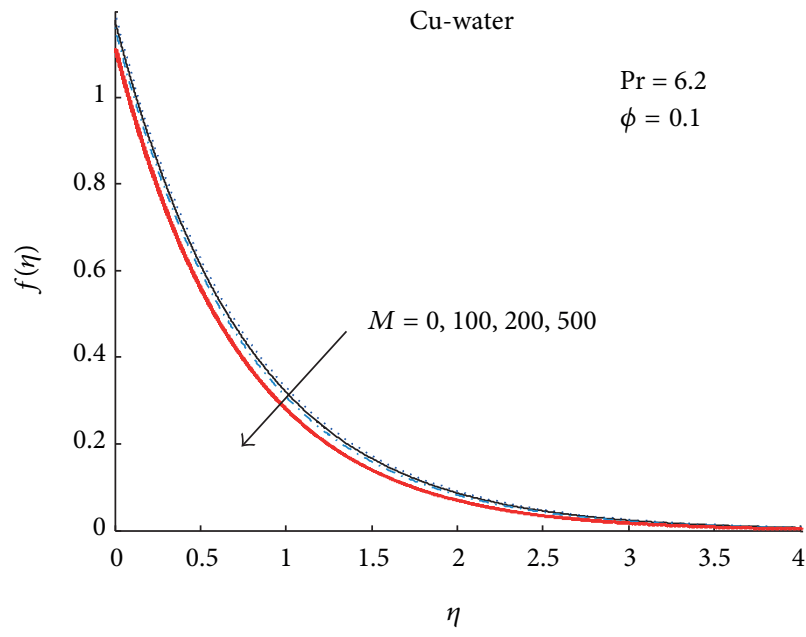

FIGURE 2: Velocity profile for $\mathrm{Cu}$ nanoparticles for various $M$.

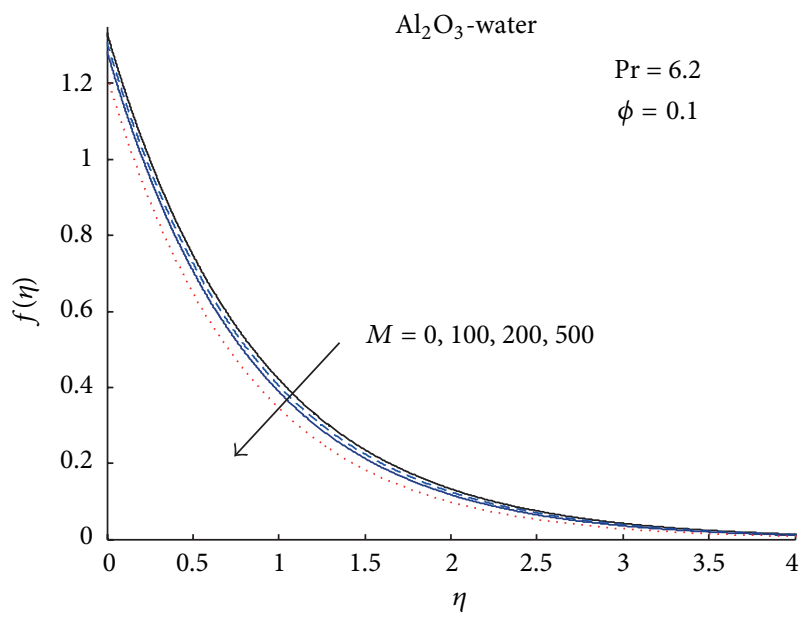

Figure 3: Velocity profile for $\mathrm{Al}_{2} \mathrm{O}_{3}$ nanoparticles for various $M$.

three different nanoparticles whose thermophysical properties were given in Table 1 . The nonlinear ordinary differential equations (10) subject to the boundary conditions (11) were solved numerically using the MATLAB "bvp $4 c$ " routine. We considered the range of nanoparticles volume fraction $\phi$ as $0 \leq \emptyset \leq 0.3$ and the Prandtl number $\operatorname{Pr}$ as $2 \leq \operatorname{Pr} \leq 8$ (for the base fluid (water) $\operatorname{Pr}=6.2$ ). The influences of the magnetic field parameter $(M)$, the nanoparticles volume fraction $(\phi)$ on velocity and, temperature and also the influence of the Prandtl number (Pr) and solid volume fraction $(\phi)$ on the Nusselt number are presented in graphs.

Figures 2, 3, and 4 display the velocity profiles, and Figures 5, 6, and 7 display the temperature profiles of $\mathrm{Cu}$ water, $\mathrm{Al}_{2} \mathrm{O}_{3}$-water, and $\mathrm{TiO}_{2}$-water, respectively, for different values of magnetic field parameter $M$. It is observed from the figures that the velocity in the boundary layer decreases and temperature increases as the Magnetic field parameter increases; this is due to the resistive force, called the Lorentz force, which is produced by the induced magnetic field within the boundary layer. 


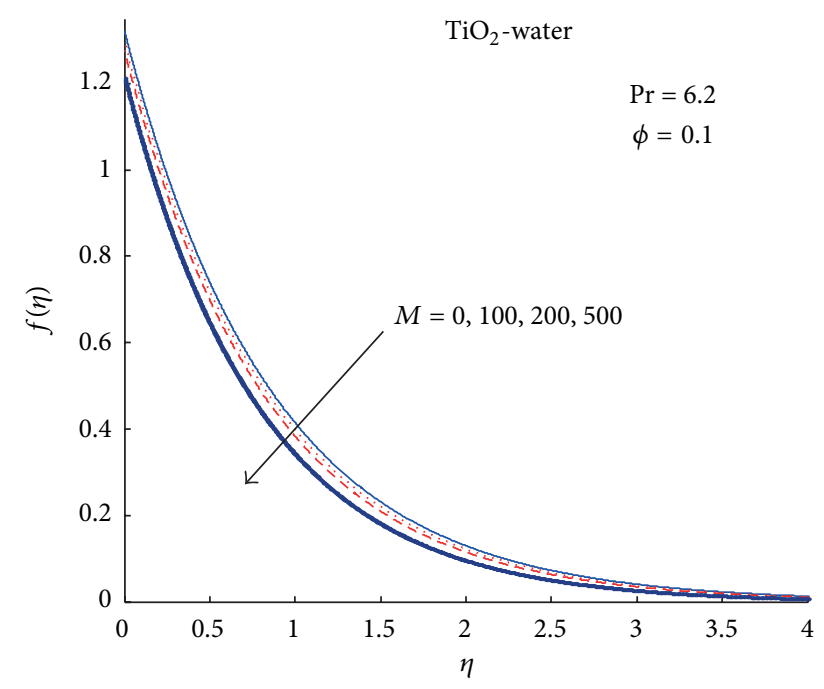

FIGURE 4: Velocity profile for $\mathrm{TiO}_{2}$ nanoparticles for various $M$.

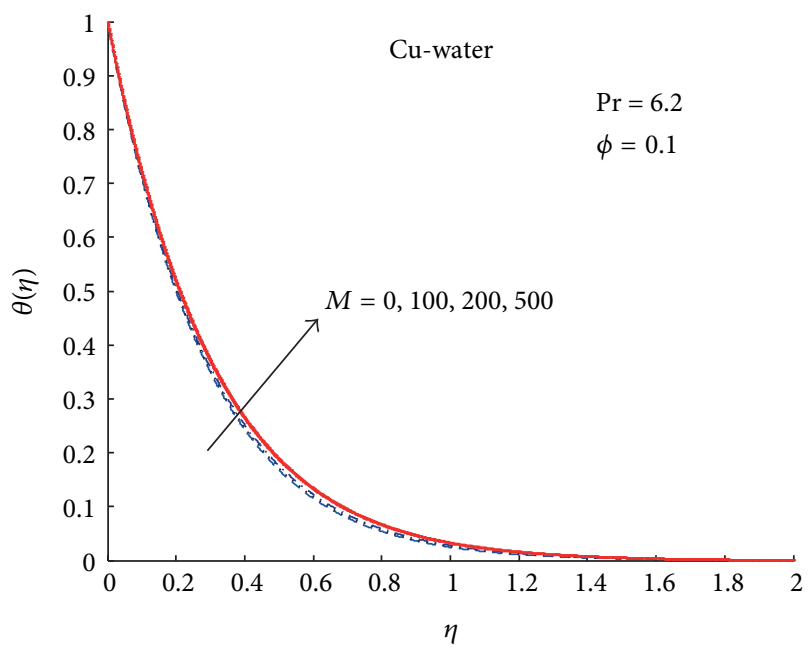

Figure 5: Temperature profile for $\mathrm{Cu}$ nanoparticles for various $M$.

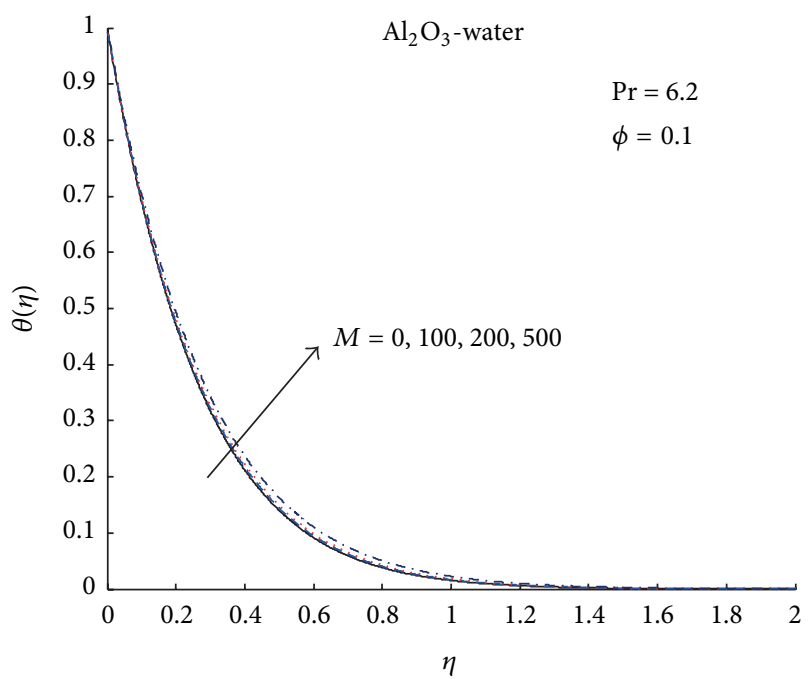

FIGURE 6: Temperature profile for $\mathrm{Al}_{2} \mathrm{O}_{3}$ nanoparticles for various $M$.

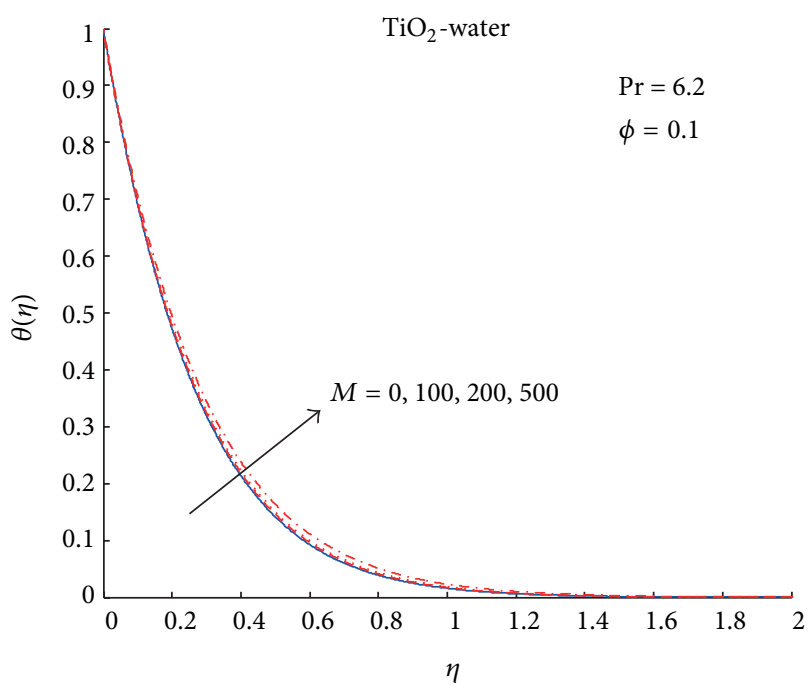

FIgURE 7: Temperature profile for $\mathrm{TiO}_{2}$ nanoparticles for various $M$.

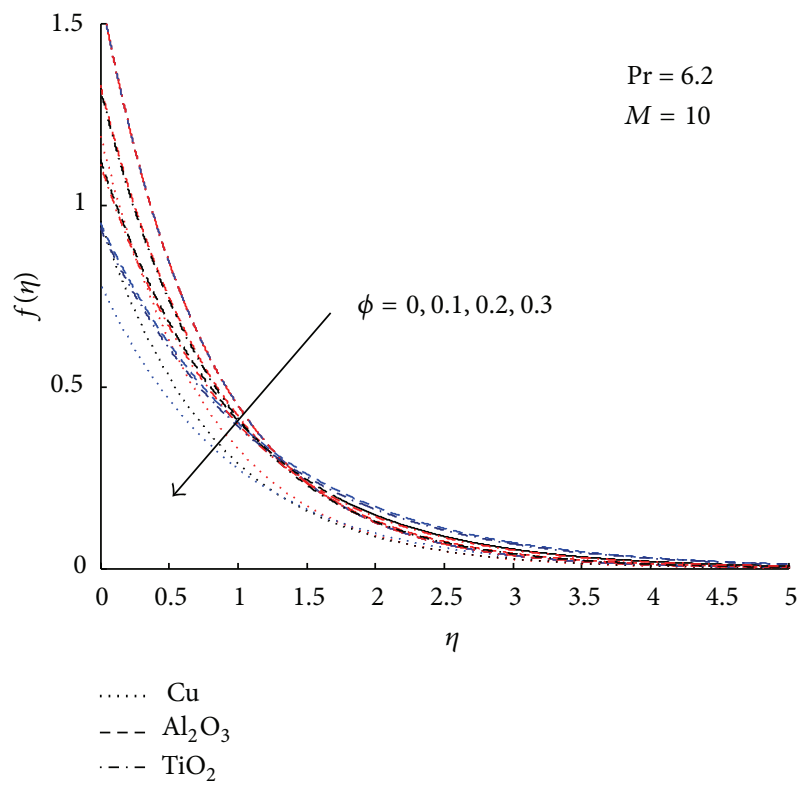

FIGURE 8: Velocity profile for different $\phi$.

Figure 8 depicts the influence of volume fraction on the velocity profile of the nanofluid particles. It is observed near the wall that velocity decreases with an increase in the volume fraction $\phi$. Also it is observed that the velocity of $\mathrm{TiO}_{2}$ nanoparticles is higher than that of $\mathrm{Cu}$ nanoparticles. From Figure 9, it is clear that an increase in the value of volume fraction enhances the temperature profile, and $\mathrm{Cu}$ nanoparticles exhibit more temperature than that of the other nanoparticles. It is also known from Figure 10 that temperature decreases with an increase in the Prandtl number. This is because of a decrease in thermal diffusivity with an increase in the Prandtl number (Pr).

Figures 11 and 12 depict the influence of the Prandtl number and volume fraction on heat transfer, respectively. It is observed that the Nusselt number increases with an 


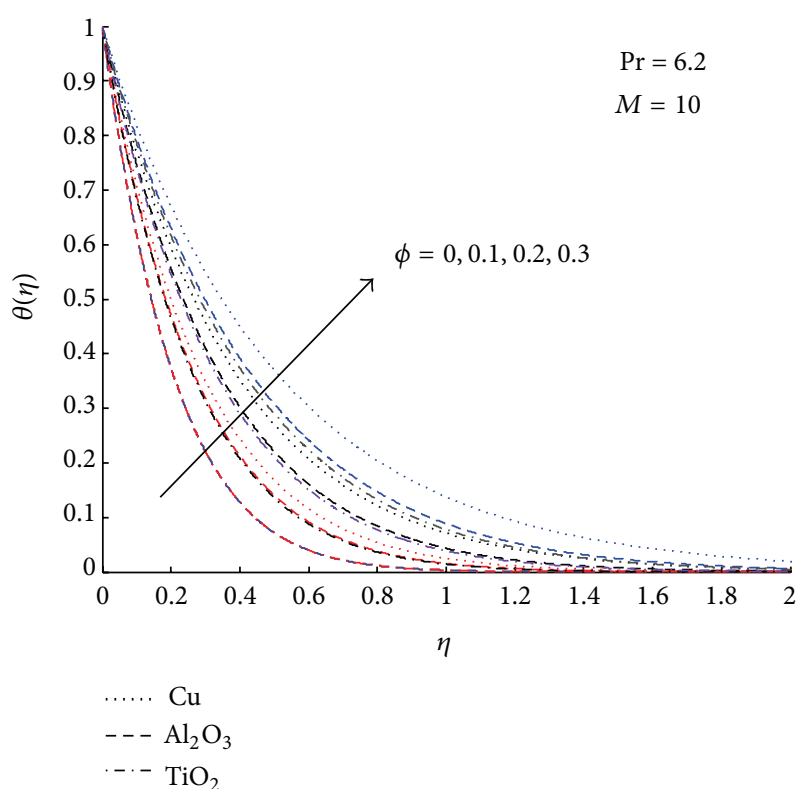

FIGURE 9: Temperature profile for different $\phi$.

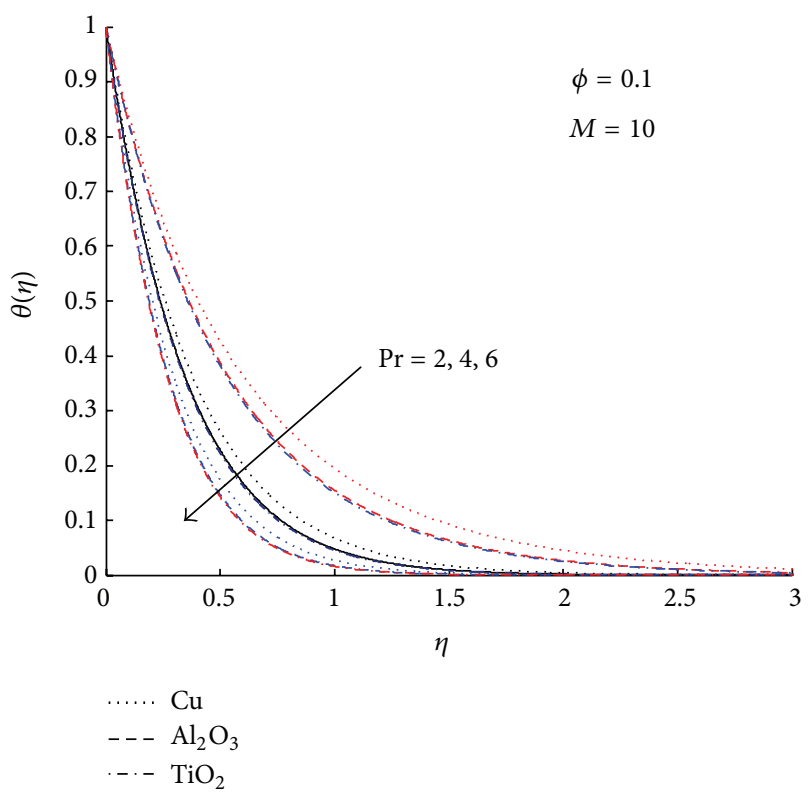

Figure 10: Temperature profile for different Pr.

increase in Prandtl number and decreases with an increase in the volume fraction.

From Table 2, it is observed that skin friction decreases with the increase in the volume fraction.

\section{Conclusion}

In the present paper, we studied the effect of heat transfer on the Marangoni boundary layer flow past a flat plate in nanofluids in presence of transverse magnetic field. With the similarity transformation, the governing equations of motion together with boundary conditions were transformed to a set

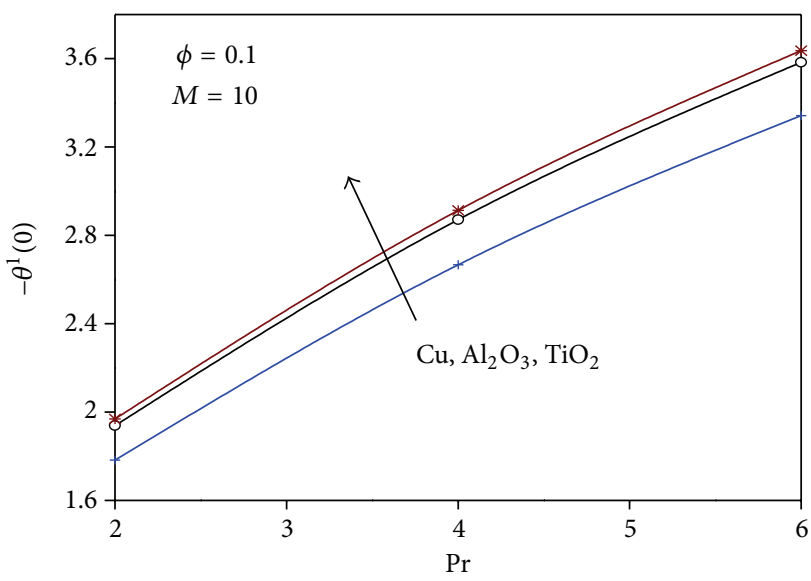

FIgURE 11: Heat transfer effect against the Prandtl number.

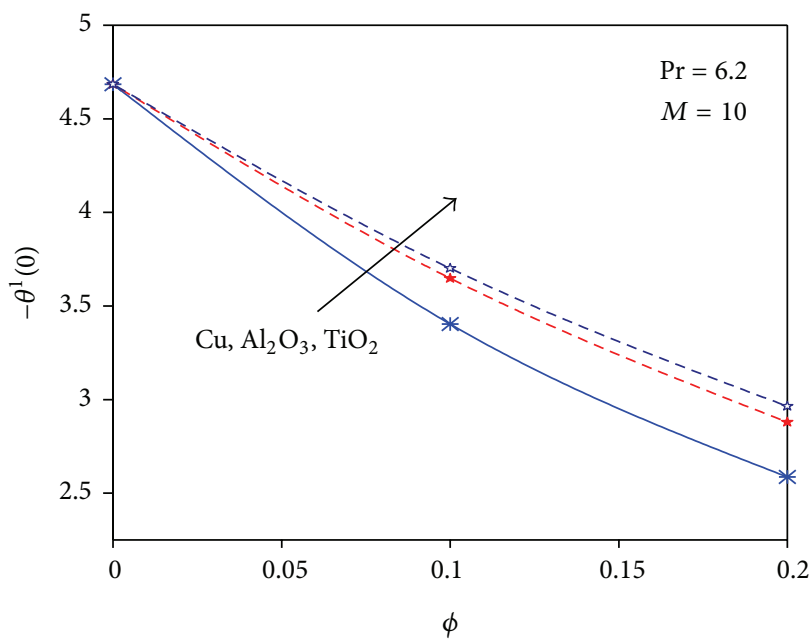

FIGURE 12: Heat transfer effect against the volume fraction.

TABLE 2: The numeric values of skin friction and the Nusselt number for various values of $\phi$.

\begin{tabular}{lcc}
\hline$\phi$ & $f^{\prime \prime}(0)$ & $-\theta^{\prime}(0)$ \\
\hline 0 & 2 & 4.68429586 \\
0.1 & 1.53686694 & 3.40361315 \\
0.2 & 1.1448668 & 2.58644151 \\
\hline
\end{tabular}

of nonlinear ordinary differential equations. The numerical solutions are then obtained for these equations by the help of MATLAB "bvp4c" programming tool. Different types of nanoparticles like $\mathrm{Cu}, \mathrm{Al}_{2} \mathrm{O}_{3}$, and $\mathrm{TiO}_{2}$ were taken into consideration with $\mathrm{H}_{2} \mathrm{O}$ as base fluid. The effects of magnetic field parameter $M$, solid volume fraction of the nanofluid $\phi$ on the velocity and temperature fields for different nano particles, and the Prandtl number Pr on temperature field were plotted and analyzed. Also the effects of the Prandtl number Pr and solid volume fraction $\phi$ on local the Nusselt number for the different nanoparticles were discussed for a fixed value of magnetic field parameter $M$. It is found that the inclusion of the magnetic field parameter on the flow 
increased the temperature and decreased the velocity fields in all types of nanofluids. A similar profile was observed on the inclusion of solid volume fraction of the nanoparticles. It was noted that presence of the Prandtl number reduced the temperature field. Also it was observed that for a fixed Prandtl number and other parameters, the rate of heat transfer is more in $\mathrm{TiO}_{2}-\mathrm{H}_{2} \mathrm{O}$.

\section{References}

[1] L. G. Napolitano, "Microgravity fluid dynamics," in Proceedings of the 2nd Levitch Conference, Washington, DC, USA, 1978.

[2] Y. Okano, M. Itoh, and A. Hirata, "Natural and marangoni convections in a two-dimensional rectangular open boat," Journal of Chemical Engineering of Japan, vol. 22, no. 3, pp. 275281, 1989.

[3] D. M. Christopher and B. Wang, "Prandtl number effects for Marangoni convection over a flat surface," International Journal of Thermal Sciences, vol. 40, no. 6, pp. 564-570, 2001.

[4] I. Pop, A. Postelnicu, and T. Groşan, "Thermosolutal Marangoni forced convection boundary layers," Meccanica, vol. 36, no. 5, pp. 555-571, 2001.

[5] E. Magyari and A. J. Chamkha, "Exact analytical solutions for thermosolutal Marangoni convection in the presence of heat and mass generation or consumption," Heat and Mass Transfer, vol. 43, no. 9, pp. 965-974, 2007.

[6] A. Al-Mudhaf and A. J. Chamkha, "Similarity solutions for MHD thermosolutal Marangoni convection over a flat surface in the presence of heat generation or absorption effects," Heat and Mass Transfer, vol. 42, no. 2, pp. 112-121, 2005.

[7] C. H. Chen, "Marangoni effects on forced convection of powerlaw liquids in a thin film over a stretching surface," Physics Letters A, vol. 370, no. 1, pp. 51-57, 2007.

[8] S. P. Jang and S. U. S. Choi, "Role of Brownian motion in the enhanced thermal conductivity of nanofluids," Applied Physics Letters, vol. 84, no. 21, pp. 4316-4318, 2004.

[9] N. M. Arifin, R. Nazar, and I. Pop, "Marangoni driven boundary layer flow past a flat plate in nanofluid with suction/injection," in Proceedings of the International Conference on Mathematical Science (ICMS '10), pp. 94-99, Bolu, Turkey, November 2010.

[10] R. K. Tiwari and M. K. Das, "Heat transfer augmentation in a two-sided lid-driven differentially heated square cavity utilizing nanofluids," International Journal of Heat and Mass Transfer, vol. 50, no. 9-10, pp. 2002-2018, 2007.

[11] J. Buongiorno, "Convective transport in nanofluids," Journal of Heat Transfer, vol. 128, no. 3, pp. 240-250, 2006.

[12] W. Daungthongsuk and S. Wongwises, "A critical review of convective heat transfer of nanofluids," Renewable and Sustainable Energy Reviews, vol. 11, no. 5, pp. 797-817, 2007.

[13] V. Trisaksri and S. Wongwises, "Critical review of heat transfer characteristics of nanofluids," Renewable and Sustainable Energy Reviews, vol. 11, no. 3, pp. 512-523, 2007.

[14] X. Q. Wang and A. S. Mujumdar, "Heat transfer characteristics of nanofluids: a review," International Journal of Thermal Sciences, vol. 46, no. 1, pp. 1-19, 2007.

[15] S. Kakaç and A. Pramuanjaroenkij, "Review of convective heat transfer enhancement with nanofluids," International Journal of Heat and Mass Transfer, vol. 52, no. 13-14, pp. 3187-3196, 2009.

[16] R. A. Hamid, N. M. Arifin, R. M. Nazar, and I. Pop, "Radiation effects on Marangoni boundary layer flow past a flat plate in nanofluid," in Proceedings of the International MultiConference of Engineers and Computer Scientists 2011 (IMECS '11), vol. 3, pp. 1260-1263, Hong Kong, March 2011.

[17] H. F. Oztop and E. Abu-Nada, "Numerical study of natural convection in partially heated rectangular enclosures filled with nanofluids," International Journal of Heat and Fluid Flow, vol. 29, no. 5, pp. 1326-1336, 2008. 


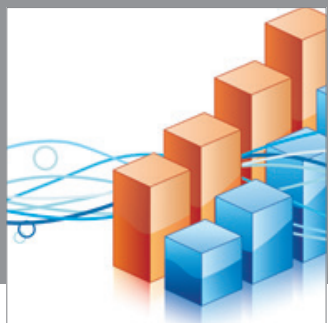

Advances in

Operations Research

mansans

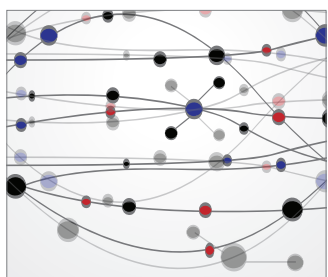

The Scientific World Journal
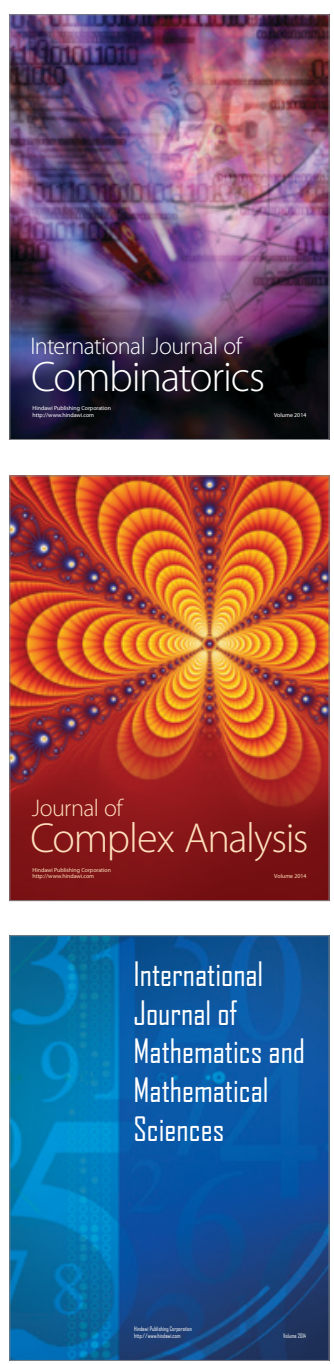
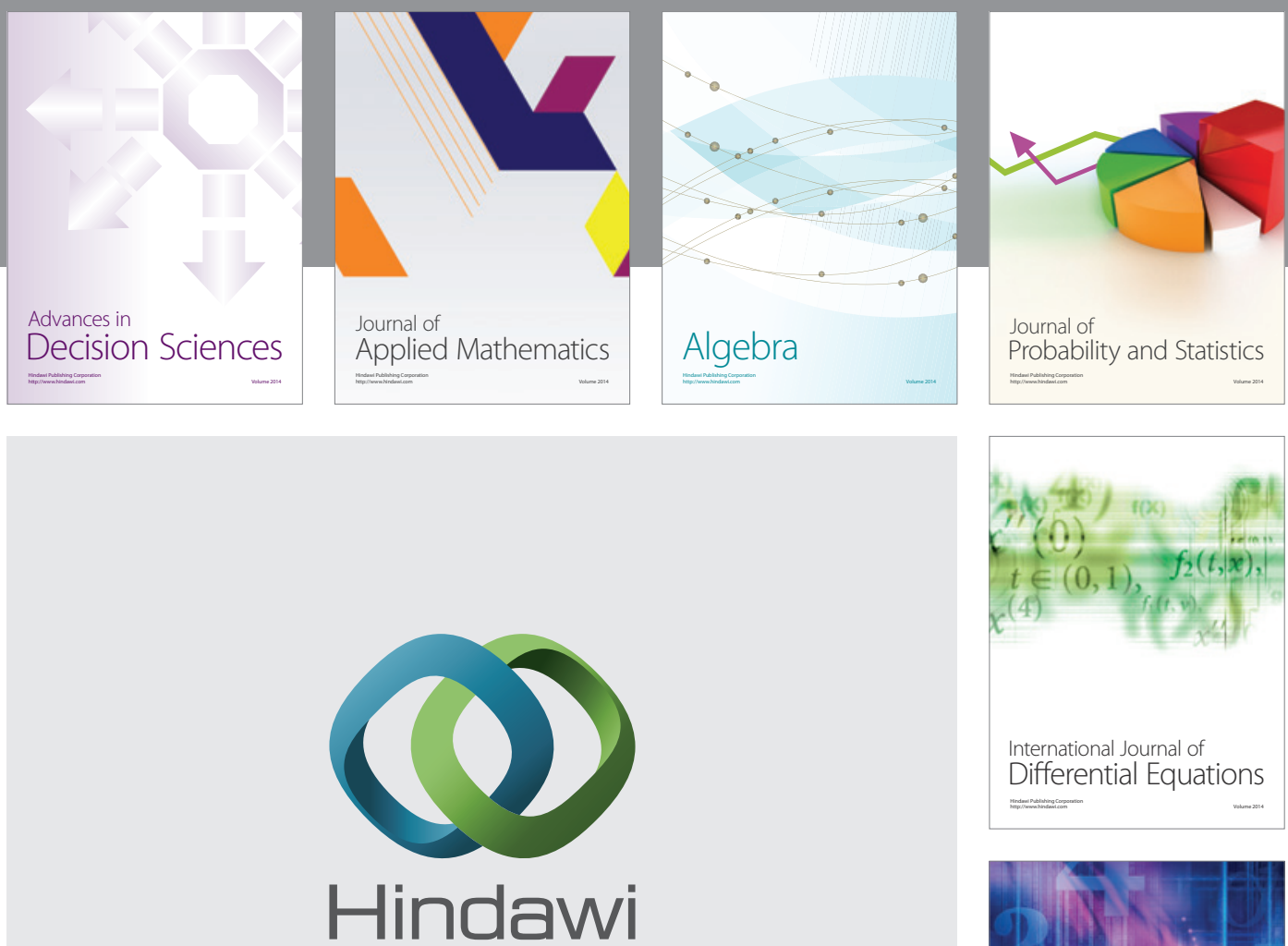

Submit your manuscripts at http://www.hindawi.com
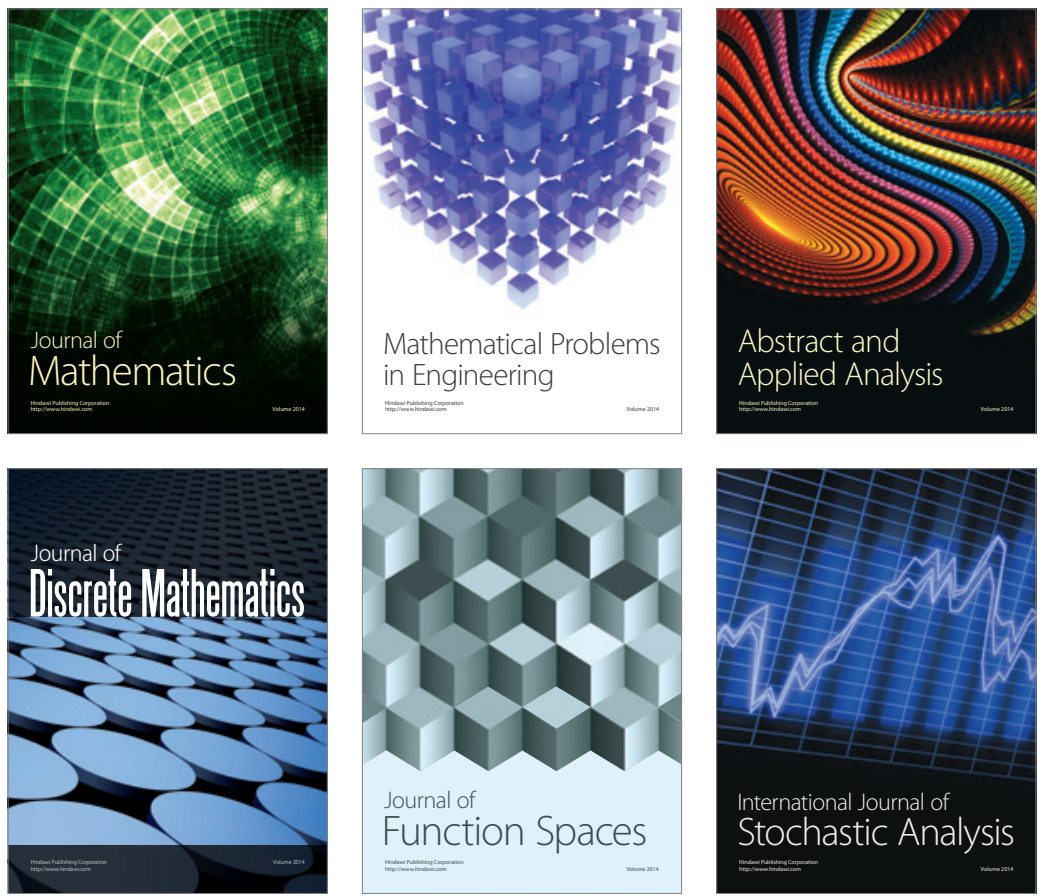

Journal of

Function Spaces

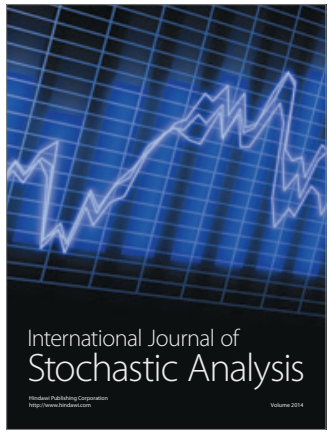

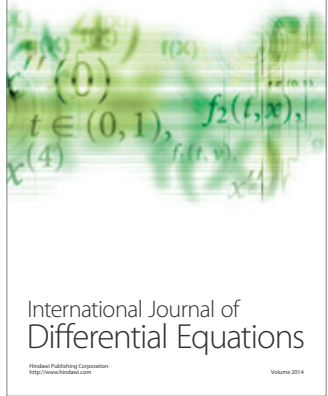
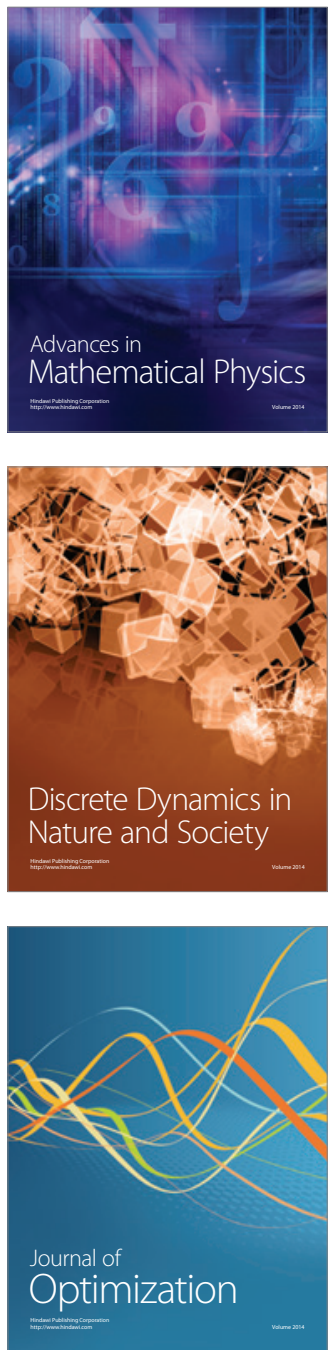